\title{
Recommendation for Reforms of the Co-ordination in the UN System
}

\author{
Igor Janev $^{1}$ \\ ${ }^{1}$ Institute for Political Studies, Belgrade, Serbia \\ Correspondence: Igor Janev, Principal Research Fellow at the Institute for Political Studies, Belgrade, St. Svetozara \\ Markovića 36, Serbia.
}

Received: March 27, 2020

Accepted: April 9, $2020 \quad$ Available online: April 28, 2020

doi:10.11114/ijsss.v8i3.4830

URL: https://doi.org/10.11114/ijsss.v8i3.4830

\begin{abstract}
Within the conceptual framework of the "financial co-ordination", in the present article, we analyzes approach to the problem of program(s) and budget co-ordination within the UN system, we have proposed a new model for co-ordination which has the potential of elimination of negative effects of the present mechanism of co-ordination in the UN system. This model is based on the idea of introducing a budgetary control mechanism into the UN inter-agency system by providing the UN General Assembly with a legal power to approve the regular (administrative) budgets of UN-related agencies (by amending paragraph 3, article 17 of the UN Charter). This amendment induces greater de jure and de facto binding power in all decisions relating to the program(s) and budget co-ordination within the UN system.
\end{abstract}

Keywords: coordination, system, agreement, statute, budget, development, agency, UN

\section{Introduction}

The problem of co-ordination of activities within the UN family of organizations has been a subject of increasing interest and numerous studies during the last six decades (Jackson, 1969; Sharp, 1966; Elmandrja, 1978; Bertrand, 1985). The issue arises from emergence of the large variety of UN-related mutually linked international agencies and wide range of their raising activities. In spite of the well-defined specific basic (Constitutional) mission(s) of each of the specialized UN agencies, the complex nature of the problems they are dealing with (e.g., in the areas of social and economic development, but also in other areas) and which often need a multi-faceted approach, necessarily leads to a certain degree of overlap of their objectives and, therefore, to the possibility of overlap of their activities as well. In such circumstances and situations the need of an inter-agency cooperation and policy co-ordination becomes evident.

In particular, a coordinated approach, based on the functional complementarity of the organizations involved, would result in an efficient, harmonized cooperation with minimum gaps and conflicts in their programs and rational use of resources (theoretically called "positive co-ordination", according to instance H. G. Schermers, 1980). The lack of such coordinated approach usually leads directly to creation of above-mentioned gaps and conflicts in the activity of the UN family of organizations in the program areas it addresses and more or less to direct duplication/multiplication of activities in this (linked) system, accompanied by waste of resources. The inherent (frequently bureaucratically driven) tendency for growth of (number of) international organizations/bodies, coupled with the unavoidable overlaps in the implementation of their statutory objectives, generates a permanent risk of multiplication of their activities, overlaps and mismanagement of resources. Administrative and policy measures (e.g., through the appropriate organs of the UN) aiming at diminishing or reducing the effects of the program multiplication phenomenon can be theoretically characterized as "negative co-ordination", whose main feature is to limit the work of one or more organizations for purpose to provide needed efficacy. This approach, however, does not address the problem in its broader context, namely harmonization of the cooperation and policies of UN-related international organizations for achieving optimal overall results by the system within the available resources. Schermers (1980, supra note 2) notes that the problem of program "harmonization" in the system of UN specialized agencies can be approached also through a mechanism of "financial co-ordination" which provides a direct correlation of the programs and regular budgets of the organizations and a possibility of dynamic and rational management of resources (e.g., by restricting the activities of one organization/agency in order to make extra funds available for new activities in another organization or agency). The "financial co-ordination" approach has many attractive features: besides an almost automatic elimination or reduction of the program duplication/multiplication issues or phenomenon, it allows establishment of a common system of priorities, common system of criteria regarding the efficient and rational use of available resources, dynamic response to emerging 
new needs, etc. However, its efficient implementation on the co-ordination of activities within the UN system of organizations implies, obviously, establishment of some sort of central control mechanism over the regular budgets of individual organizations (agencies). This delicate legal and political issue can be approached in different ways, with a varying degree of necessary changes in the existing administrative and functional structures of the system and apparently its (in the first place basic) legal documents. In his classical study on the capacity of UN development system, Jackson (1969) suggested a partial solution based on the concentration of all UN economic development technical activities and associated funds into one UN program (the UN Development Program). The UN specialized agencies would then play the role of "executive agencies" in the implementation stage of selected programs with significantly smaller influence on the overall program and budget distribution in the UN system for development purposes. However, the range of activities of UN-related organizations is much broader than the economic development area and, correspondingly, the problem of their co-ordination is much more complex.

Adopting the "financial co-ordination" approach as a conceptual framework, in the present article we shall make an effort to formulate a model for reconstruction of the present system of co-ordination between the UN and specialized agencies and among the specialized agencies themselves which is intended to be comprehensive and to encompass practically all major activities within the UN system of organizations. The model is based on the suggestion of introducing a specific mechanism of budgetary control within the UN system of organizations which provides an automatic and direct impact on their co-ordination (e.g., elimination of the activity duplication problem). The implementation of this model will require a certain level of reform of relations between the UN and UN-related agencies and introduction of certain revisions in the UN Charter and in the statutes of specialized agencies. Other recent concepts of reforms related to finanacial issues were concted to the UNDP and the United Nations Sustainable Development Group (previously known as United Nations Development Group-UNDG). ${ }^{1}$ The Delivering as One concept was also introduced. The main normative instrument for reforming the UN development system is the Quadrennial comprehensive policy review (QCPR). Following an assessment of progress, this General Assembly resolution which designs and gives mandates to the UN system to better address reform objectives is negotiated every four years. ${ }^{2}$ Other proposals for reforms included removal of spent provisions in UN Charter or in by-laws if provisions of the United Nations Charter are no longer relevant.

\section{The Present Model of Co-ordination within the UN}

The present model of co-ordination within the UN system is based on the provisions contained in articles 17, 57, 58, 63 and 64 of the UN Charter. ${ }^{3}$ Articles 57 and 63 of the Charter provide(s) for the establishment of agreements between the UN and the specialized agencies, as major instruments regulating their mutual relations. ${ }^{4}$ Article 58 of the Charter gives UN the power only to "make recommendations for the co-ordination of policies and activities of specialized agencies". ${ }^{5}$ The practical extent of these powers (and the corresponding legal obligations of the agencies), however, can be seen in article 64 of the Charter where it is provided that the UN Economic and Social Council (ECOSOC) may only take "appropriate steps to obtain regular reports from the specialized agencies" and make "arrangements with the Members of the United Nations and with the specialized agencies to obtain reports on the steps taken to give effect to its own recommendations and to recommendations on matters falling in its competence made by the General Assembly." ${ }^{6}$ The powers of ECOSOC are so limited that it may only communicate its "observations on these reports to the General Assembly". ${ }^{7}$ The "arrangements" mentioned in article 64 of the Charter are to be interpreted as "administrative instruments" which have a relatively "weak binding power" and represent part of the internal law of international organizations. Indeed, according to the interpretation of the Legal Department of UN, the term "arrangement" in article 64 of the Charter does not refer to a formal agreement. The weak binding force of these instruments particularly distinguishes them from the (common/usual or "regular") treaties made under the international law. However, it should be pointed out that in determining the legal character of an "arrangement" its purpose and content have primarily to be

\footnotetext{
${ }^{1}$ See Remarks by U.N. Secretary-General Kofi Annan at United Nations General Assembly Session, United Nations Headquarters, Federal News Service, 22 September 1997.

${ }^{2}$ See for example the United Nations General Assembly resolution 67/226, Quadrennial comprehensive policy review of operational activities for development of the United Nations system.

${ }^{3}$ See Charter of the United Nations

${ }^{4} I d$., art. 57 and art. 63.

${ }^{5} I d$. , art. 58.

${ }^{6} I d$., art. 64, para 1.

${ }^{7} I d$., art. 64, para 2.
} 
taken into account. For instance, arrangements between the UN (or any UN-related organization) with Member States related to the functioning of the organization (e.g., arrangements for sending delegations to the sessions of a particular organ of the organization or to pay in a particular way the member's regular budgetary contribution to the organization, etc.) can be generally regarded as internal (or administrative) "arrangements". These instruments are generally governed by the internal law of the organization and create part of its internal administrative law. On the other hand, Member States willing to accept additional obligations towards the organization, which are not contained even implicitly in the organization's internal rules, may conclude binding arrangements with that organization, which could be regarded as agreements governed by the public international treaty law. Difficulties in determining the "legal nature" of such instruments may also arise from problems in the interpretation whether some provisions are based or not on the internal rules of the organization, or because of the mixed character of the provisions contained in the instrument. Thus, it should be pointed out that even the "subjects of an arrangement" need not to be a sole decisive factor in determining the legal character of the arrangement; in each case due consideration of the purpose, context and substance of the instrument is necessary.

Legally very similar to the arrangements mentioned in article 64 of the UN Charter are the agreements (other instruments) between the UN and the specialized agencies, as well as (such instruments-arrangements) between the individual agencies themselves. We may note that these arrangements contain primarily provisions related to their administrative co-operation and co-ordination. Based on their content, the legal character of these agreements ${ }^{8}$ is similar to the so-called "internal agreements" between different organs of the same international organization (the latter being governed by the internal rules of the organization and not by the international treaty law). The agreements between the UN and specialized agencies essentially do not contain effective legal obligations or binding provisions for their effective enforcement. In this respect they are even of "lesser binding power" than the internal "agreements" within the international organizations. The range of questions most often covered by these administrative agreements includes: reciprocal representation, proposals for agenda items, mutual consultations and recommendations, exchange of documents and information, administration of technical and statistical services, relationship to main UN organs (including reporting of the agencies to the $\mathrm{UN}$ ), administrative and budgetary co-ordination and harmonization, relationship concerning informing ECOSOC of the agreements concluded mutually among the organizations in the UN system, liaison and other similar arrangements between the UN and the agencies. ${ }^{9}$ The range of questions usually covered in the mutual agreements among the specialized agencies themselves is more specific (often with program related provisions), but essentially of similar nature. ${ }^{10}$ Therefore, on the basis of their content, it can be argued that the existing instruments regulating the co-ordination within the UN system are primarily of administrative nature and of lesser binding power and, as such, they do not essentially serve their basic purpose (i.e., enhancement of the co-ordination). As a result, the present model of co-ordination of the policies and activities of the UN related organizations is rather inefficient and generates the entire range of adverse effects discussed previously here in the Introduction of this article.

The above analysis has shown that the co-ordination problem within the UN system is closely connected with the content and legal nature of the "links between the UN and the specialized agencies. In the same context, because of the negative financial effects associated with its apparently improper solution(s), the co-ordination issue also appears as a real problem of efficient management of available resources, on both the system's and individual organization's level. The "co-ordination issue" is, therefore, closely related to the budgetary arrangements within the UN system and with the increasing need for budgetary control in the system of linked agencies. Not surprisingly, the requests for reconstruction of the system of relations between the UN and the specialized agencies (including the question of co-ordination) are usually raised in times of budgetary crises in the UN system and are paralleled (or combined) with requests for a tighter control of the regular budgets of the organizations.

The need for redefinition and reconstruction of the system of relations between the UN and the specialized agencies with the aim of improving efficiency of the entire system (including its co-ordination) has been recognized already during the fifties. With the dramatic increase of the budget(s) and administration(s) in the UN family of organizations

\footnotetext{
${ }^{8}$ See, e.g., Agreement between the UN and the International Bank for Reconstruction and Development, or (as an example for inter-agency agreements) Agreement between Food and Agriculture Organization of the UN and the UN Industrial Development Organization.

${ }^{9}$ See supra note 11 .

${ }^{10}$ See, e.g., Memorandum of understanding with respect to working arrangements between the Food and Agriculture Organization of the UN and the IBRD and IDA; Agreement between the IFAD and FAO; Agreement between the FAO and UNIDO.
} 
during the sixties, the problem became particularly acute. Attempts of finding an adequate solution for this issue have resulted in the already mentioned study of Jackson (1969, supra note 1) proposing integration of all UN development activities and the corresponding financial resources. The implementation of the findings of this study has been only partial, and the problem remains essentially open until the present day. Similar proposals for partial integration and centralization of the activities, programs and financial resources in the UN system have been increasingly put forward during the seventies and eighties, including the UN General Assembly resolution 32/12 $7^{11}$, the studies of the UN Joint Inspection Unit (Bertrand, supra note 1) and the study of the UN Association of the USA ${ }^{12}$, etc. The last two studies have suggested particularly radical reforms in the UN system, such as merger of some of the UN organs (e.g., ECOSOC and UNCTAD) and severe financial control and budgetary restrictions. Many UN General Assembly resolutions in the nineties also stress the ultimate need for urgent reforms in the budgetary field. ${ }^{13}$

As pointed out earlier, the budgetary arrangements within the UN system are closely related with the administrative and management aspects of the organizations (e.g., the program and budget planning process, decision making process, activity results evaluation), including their performance and internal co-ordination. A budgetary reform of the system may, therefore, be the only efficient instrument for the administrative and structural reform of the UN-related organizations, and could have an appropriate impact on their efficiency. As argued in the recent study of Beigbeder (1989), the financial crisis in the UN system has a substantial effect on the decrease of effectiveness and performance of the UN organizations. Indeed, the financial crisis in the nineties produced significant adverse effects on the programs of large UN agencies, such as FAO, ILO, UNESCO and WHO. ${ }^{14}$ Even the organizations with substantial percentage of extrabudgetary funding, such as UNIDO, have been (and still are) facing serious financial problems with deleterious effects on their programs.

It is fairly obvious that the present financial crisis in the UN system is (at least) partly due to the uncorrelated and functionally uncontrolled expansions of the activities of UN-related agencies during the last three-four decades, which resulted in a significant and unnecessary degree of program duplication/multiplication and activity evident overlap in the organizations, particularly those with similar statutory objectives and program goals. This was possible because of the lack of an adequate centralized system of co-ordination within the UN system. The present model of co-ordination within the UN system does not ensure an "integrated" approach to the co-ordination and planning process and does not contain an effective administrative mechanism for oversight and control of the program and budget correlation and activities on the level of the entire UN system.

As we have seen at the beginning of this section, the legal instruments which presently "regulate" the co-ordination within the UN system do not have sufficiently strong binding force and do not contain proper provisions for effective budgetary control and coordinated behavior. On the other hand, the provisions incorporated or enshrined in the statutes/constitutions and other basic documents of UN-related organizations or agencies enable them with a high degree of administrative and budgetary autonomy vis a vis (or from) the United Nations. Therefore, a possible way of reforming the system of co-ordination within the UN system is to introduce appropriate revisions in the basic legal documents of the UN and specialized agencies which define their mutual relations and co-ordination. The basic idea of the model proposed for this purpose (in the next section of our article) is to enable the UN General Assembly with a legal power for control over the regular budgets of the UN-related organizations (thus limiting their budgetary autonomy) and to strengthen the role of ECOSOC in the field of inter-agency co-operation and co-ordination. The objective of our proposed model is to establish a coherent and efficient system of co-ordination in the UN system with stronger programmatic and budgetary correlation. We shall try to formulate the model with minimum required revisions in the legal documents of the UN and basic instruments of the agencies.

\section{Outline of the Proposed Model for Co-ordination}

Based on previous discussion here (above), the simplest efficient way to empower the UN General Assembly with an appropriate mechanism of control over the administrative and regular budgets of the UN agencies and, thus, with a certain level of control or centralized mechanism of their programs, is the revision of paragraph 3 of article 17 of the UN Charter. This paragraph presently provides: "The General Assembly shall consider and approve any financial and budgetary arrangements with the specialized agencies referred to in article 57 and shall examine the administrative budgets of such specialized agencies with a view to making recommendations to the agencies concerned." While the

\footnotetext{
${ }^{11}$ See UN General Assembly Resolution 32/197 (1977).

12 A Successor Vision: the UN of Tomorrow, UN Association of the USA (1987).

${ }^{13}$ See, e.g., UN General Assembly Resolution 45/236 (1990)

${ }^{14} I d$., sect. II.4, p. 10.
} 
first part of this paragraph relatively "empowers" the UN General Assembly to "control" the financial and budgetary arrangements of the UN with the specialized agencies (by taking the decision only regarding their approval), the second part of this paragraph evidently does not contain the appropriate legal power of the General Assembly over the administrative budgets of the agencies. The UN agencies determine their administrative budgets entirely autonomously and the practical binding force of the "recommendations" in the context of the present formulation of the paragraph is insufficiently strong to produce any real controlling effect on the budgets, activities and programs of the agencies. Indeed, the entire practice of the work of the UN system demonstrates that the provisions in the second part of the above-cited paragraph 3, article 17 of the Charter do not provide an effective and needed mechanism to restrain the uncontrolled budgetary and programmatic expansion of the agencies and their administration or bureaucracy.

In order to achieve the basic requirement of establishing an effective system of controlled co-ordination within the UN system in the budgetary and programmatic areas, in our view, it is necessary to enable the UN General Assembly with a legal power to control the administrative and regular budgets of UN specialized agencies by amending the second part of paragraph 3, article 17 of the Charter in such a way that the General Assembly not only examines but also approves the administrative and regular budgets of specialized agencies. This new legal power of the General Assembly is the key element of the control mechanism over the programs of the agencies which should produce an almost automatic effect on the program co-ordination and coordinated behavior i.e. bureaucracy expansion and overleaping activities. Since the program and budget planning process in the specialized agencies is usually long (two or more year cycles), the legal power of the General Assembly to examine the agency budgets and provide recommendations regarding them to the agencies could further be retained and used as a control power during the planning process and execution. Of course, the power to examine the agencies' program and budget proposals, the General Assembly can delegate to some of its subsidiary organs (such as the Fifth Committee of the Assembly), or to some of the major UN organs (e.g., ECOSOC and its subsidiary organs). The amended version of paragraph 3, article 17 of the Charter could, thus, read: "The General Assembly shall consider and approve any financial and budgetary arrangements with the specialized agencies referred to in article 57 and shall examine the administrative and regular budgets of specialized agencies with a view to making recommendations to the agencies concerned and shall approve them."

The proposed amended second part of paragraph 3, article 17 of the Charter implies that the approval of the administrative and regular budgets of UN specialized agencies is not only a "formal requirement" but part of a controlling co-operative process during which the necessary policy, budgetary and programmatic global co-ordination in the system of UN-related agencies can be achieved. It should be also noted that in the new recommended version of paragraph 3, article 17 of the Charter, the actual binding force of the "recommendations" (made by the General Assembly or the corresponding organ to which the recommendation making power is delegated) is much "stronger" than in the existing present version of this paragraph, because they are now in a direct relationship with the budget approval.

The provision of authority to the UN General Assembly to approve the budgets (and associated programs or activities) of the specialized agencies does mean a complete limitation of their budgetary autonomy, but only with regard to their administrative (i.e., regular) budgets. However, this concentration of the power in the UN system does not mean an absolute administrative, bureaucratic restrain of the activities of the agencies. Rather, it provides a legal setting for a process of coordinated planning of all activities in the UN system in accordance with certain commonly accepted policies and priorities, unified criteria and mutual complementarity and interests of member-states (that are essentially same countries in the all agencies and the UN). This same legal framework ensures also an integral approach to the economic and social development and other problems addressed by the UN system, a flexibility in restructuring the programs and activities according to the evolving conditions and needs, and thereby a rational management of the available (common) resources.

The implementation of the proposed model for co-ordination optionally could be entrusted to the Fifth Committee of the General Assembly and to ECOSOC, the latter of which, according to the UN Charter and other documents, already has the responsibilities for oversight and supervision of the co-ordination within the UN system. In particular, the standing Committee for Program and Co-ordination, which is a subsidiary organ of both ECOSOC and the General Assembly for harmonizing the programs and activities of UN-related organizations, can be additionally empowered in such a way that its recommendations, formulated in consultation with other UN General Assembly organs (such as the Assembly main committees, the Administrative Committee on Co-ordination, the UN Advisory Committee on Administrative and Budgetary Questions), impose essentially stronger actual and effective obligations or duties on the agencies.

It is furthermore self-evident or obvious that the above-proposed (recommended) revision of paragraph 3, article 17 of the UN Charter will require appropriate revisions in the statutes and other basic legal documents of UN-related organizations, as well as in the legal documents (agreements) regulating the relations between the UN and the agencies.. 
In the statutes of all UN-related agencies which contain provisions relating to their "administrative budgets", the corresponding articles have to be amended by an additional provision which states expressly that the agency regular (administrative) budget is subject to approval (or "final approval") by the UN General Assembly. This is the case with the statutes of all UN-related agencies, except with those of the International Monetary Fund and the World Bank Group. In the last two cases, the relevant provisions relating to the "administrative budgets" are contained in their by-laws and, consequently, amendments should be made in the corresponding articles there.

For instance, paragraph 1, article XVIII of the Constitution of FAO ${ }^{1521}$ should be amended in a way which provides that the budget of this agency will be subject to approval by both the Conference of FAO, as a supreme organ of this organization, and the General Assembly of the United Nations. In the case of the IBRD, a similar revision should be made in section 18 (b) of its by-law, respecting specific nature of this financial institution and its budget (and resources). ${ }^{1622}$

The way in which these amendments of constitutional nature are made could vary from agency to agency. In those agencies where the total agency budget contains explicitly two main components, one coming from the regular contributions of its Member States (so-called regular budget) and the other coming from various "extra-budgetary" sources, the supreme governing agency bodies should still retain the power of approving the total agency budget. The amendment of the corresponding article should then provide that the "regular" part of the total budget is subject to final approval by the General Assembly. Since both parts of the budget are functionally connected through the activities of the corresponding agency, and since their approval is in the jurisdiction of the agency's authorized body ${ }^{1723}$, the power of this body over the agency budget remains still substantial, but not uncontrolled. This indicates that the agencies with significant extra-budgetary resources only partly lose their financial autonomy.

Another category of legal documents which need certain revision within the recommended/proposed co-ordination model are the agreements (administrative arrangements) between the UN and the specialized agencies. The purpose of these revisions is threefold: (i) to bring them into conformity (accordance) with the introduced new amendments in the UN Charter and in the statutes/constitutions of the agencies, (ii) to establish the legal and institutional basis for strengthening the co-ordination between the agencies on program and budgetary matters, and (iii) to incorporate the control and supervising mechanism over the program and budget planning process. These revisions should be done in a uniform way.

Along the lines of above-mentioned objectives, the agreements (arrangements) between the UN and the International Monetary Fund, and between the UN and the International Bank for Reconstruction and Development (which are identical, except for the names of organizations) will require revisions of articles I, IV and X. ${ }^{1824}$ In paragraph 2, article $\mathrm{I}$ and in article $\mathrm{X}$ in both agreements, the provisions referring to their "independence" and "autonomy" should be removed. In paragraph 2, article IV in both agreements, it should be provided that the UN can make recommendations to these agencies (among others, also regarding budgetary matters), in a similar way as provided for other agencies. Finally, in article $\mathrm{X}$ of these agreements it should be provided that the administrative budget of the agency is subject to approval by the agency's authorized organ and by the UN General Assembly as well. ${ }^{1925}$ Similar amendments, which empower the General Assembly to approve the administrative (regular) budgets of the agencies, should be also made in the agreements of the UN with non-financial agencies. The effects of these amendments on the character of the UN-agency relations would be even more significant, because many of these agencies are financed predominantly through their regular budgets. Thus article IV in the Agreement between the United Nations and the Food and

\footnotetext{
15 See Constitution of Food and Agriculture Organization of the United Nations, art. XVIII.

${ }^{16}$ See By-Laws of the International Bank for Reconstruction and Development, sect. 18(b).

${ }^{17}$ Except in the case of the International Monetary Fund and the World Bank Group, the authorized body for budget approval is always the General Conference of the agency.

${ }^{18}$ See Agreement between the United Nations and International Monetary Fund, and Agreement between the United Nations and the International Bank for Reconstruction and Development.

${ }^{19}$ In order to protect the interests of the members of financial agencies with largest quotas and avoid possible stalemates in the approval of their administrative budgets by the General Assembly (e.g., by actions of the majority of developing countries), an amendment in the agreements between the UN and these agencies may have to be introduced which limits the power of the General Assembly to alter the administrative budgets of these agencies, adopted by their authorized organs, by not more than a certain percentage. Such a safeguarding provision would not entail further revisions neither in the statutes of these organizations nor in the UN Charter.
} 
Agriculture Organization ${ }^{2026}$, and article 17 in the Agreement between the United Nations and the UN Industrial Development Organization ${ }^{2127}$ have to be revised to reflect the approving power of the General Assembly over their administrative (regular) budgets, as already provided for in the UN Charter and their statutes. The amendments of this type in the UN-agency agreements not only make them consistent with the proposed revisions in the UN Charter and in the statutes of the agencies but also establish the legal and institutional basis for the budgetary control in the system.

In order to establish a stronger influence and control over the inter-agency co-ordination on program and budgetary matters, it would be recommendable to introduce further amendments in the UN-agency agreements. This can be achieved if the articles in these agreements which provide that ECOSOC should be informed by the agencies about the concluded inter-agency agreements (including their nature and scope) ${ }^{2228}$ are amended with provisions by which: (a) the concerned agency shall make arrangements with other UN-related agencies, where appropriate, with the purpose of co-operation and co-ordination of their program policies, activities and budgets, and (b) the ECOSOC shall be informed about the conclusion of such agreements, shall make recommendations to the agencies concerned regarding these agreements and shall approve them.

These provisions (relating approval) give a legal and institutional basis for practical and effective sort of enforcement of the centralized co-ordination of the agencies on program and budgetary matters, and a mechanism for global control and supervision of the content and legal quality of inter-agency agreements. The control over the program and budget planning and implementation process with the purpose of achieving the objective of inter-agency co-ordination can be (finally) established through a UN General Assembly resolution (or resolutions) which re-iterates the role and responsibility of its own and ECOSOC's relevant subsidiary organs (such as the Committee on Program and Co-ordination, the Administrative Committee on Co-ordination and the Advisory Committee on Administrative and Budgetary Questions) for harmonization of the programs and budgets of agencies in their planning stage and, possibly, in their implementation stage as well.

By introducing these amendments in the UN-agency agreements, these documents obtain new legal quality and higher degree of implicit (i.e., de facto) general binding power. Moreover, they consequently introduce strong binding features in the inter-agency agreements in the area of program and budget co-ordination, so that no substantial revisions of the existing provisions in these agreements are necessary. The introduced amendments in the UN-agency agreements provide ECOSOC with a power for control of the program and budget co-ordination process on both the inter-agency level and on the level of the entire UN system.

The imposed demand on the agencies to enter into mutual relationships (where appropriate) "with the purpose of co-operation and co-ordination of their program policies, activities and budgets" creates a broad basis for program and budget co-ordination on inter-agency level ("horizontal co-ordination") on which the program and budget optimization can most easily be achieved. With this step successfully performed, the previously discussed co-ordination, supervision and control on the level of ECOSOC (through the General Assembly and ECOSOC subsidiary organs) becomes much easier. Thus, the program and budget co-ordination in the UN system becomes two-dimensional: the "horizontal" co-ordination on the inter-agency level ensures program optimization (e.g., elimination of program duplication and gaps, establishment of joint programs, optimal use of resources, etc.), while the "vertical" co-ordination, implemented through ECOSOC and its machinery, provides a control mechanism for achieving an integral programmatic and budgetary self-consistency of the overall co-ordination process.

\section{Conclusion}

Within the conceptual framework of the "financial co-ordination" approach to the problem of program and budget co-ordination within the UN system, we have proposed a model for co-ordination which has the potential of fundamental elimination of negative effects of the present system of UN co-ordination and can, thereby, improve the overall efficiency of the UN system. The recommended model is based on the idea of introducing a budgetary control mechanism into the UN system by providing the General Assembly with a legal power to approve the regular (administrative) budgets of UN-related organizations (by amending paragraph 3, article 17 of the UN Charter). This amendment has significant consequences on the nature of the relations between the UN and specialized agencies and automatically induces greater de jure and de facto binding power in all decisions and documents relating to the program

\footnotetext{
20 See Agreement between the United Nations and the Food and Agriculture Organization of the United Nations, art. IV.

21 See Agreement between the United Nations and the UN Industrial Development Organization, art. 17.

22 See, e.g., Agreement between the United Nations and the International Bank for Reconstruction and Development (article XI), or Agreement between the United Nations and the United Nations Industrial Development Organization (article 13).
} 
and budget co-ordination within the UN system. The model also provides ECOSOC (by appropriate amendments in the agreements between the UN and specialized agencies) with an effective control and supervising power over the program and budget planning process in the system and over the inter-agency co-operation and co-ordination. The legal framework of the recommended model, presented in this article, is designed with minimum amendments in the existing legal documents which regulate the co-ordination area in the UN system, and mainly utilizes the induced implicit binding effects of the budget control mechanism itself. Major structural changes in the existing UN system are also not required by the proposed model.

The proposed co-ordination model has many attractive features from the point of view of improving the overall efficiency of the UN system. Because of the introduced control factor, problems such as program multiplication, uncontrolled expansion of activities, and administration, irrational management of resources, can be relatively easily eliminated. The integrated character of the co-ordination process within the model, however, allows also to make full advantage of the diversity and complementarity of agency programs (e.g., for addressing complex development problems through joint agency programs), to avoid gaps and conflicts in the activities, to improve the coherence of agencies' policies and programs, to establish a common system of priorities and criteria, all of which contribute to a more effective use of available resources. This same feature of the co-ordination model provides the UN system with an element of programmatic flexibility and responsiveness to the changing conditions and new emerging needs.

\section{Acknowledgements}

This research has been funded by the Ministry of Science and Technological Development of the Republic of Serbia

\section{References}

Beigbeder, Y. (1989). Administrative and Structural Reform in the Organizations of the UN Family. UNITAR LSA 351.1(04) I61 UNITAR/ST/29.

Bertrand, M. (1985). Some Reflections on the Reform of the United Nations. UN JIU/Rep.85/9, Geneva.

Elmandrja, M. (1978). The United Nations System. Coordinating Its Economic and Social Work, UNITAR.

Jackson, R. G. A. (1969) A Study of the Capacity of UN Development System UN. New York (1969).

SchermerS, H. G. (1980). International Institutional Law. Sijthof and Nordhoff.

Sharp, W. R. (1966). Program Coordination and the ECOSOC. In UN Administration of Economic and Social Programs (Mangone, G.I., ed.). Columbia Univ. Press, New York. https://doi.org/10.7312/mang94488-009

\section{Copyrights}

Copyright for this article is retained by the author(s), with first publication rights granted to the journal.

This is an open-access article distributed under the terms and conditions of the Creative Commons Attribution license which permits unrestricted use, distribution, and reproduction in any medium, provided the original work is properly cited. 